\title{
Application of nanotechnology for underground roof bolting
}

\author{
MS Venkata Ramayya \\ The Singareni Collieries Company Limited \\ Ramagundam, India \\ vrml@rediffmail.com
}

\begin{abstract}
Rock re-inforcement in Underground Coal mining is generally being done by roof bolting. Roof bolting is a pre-requisite and important activity for safety and high percentage of productive extraction of the Coal from Underground Coal mining. Nanotechnology and Nanoscience is the latest development in science and technology. Nano material based products for different applications are studied. Nano based material for roof bolts and Nano silicate based capsules for grouting can be used in roof bolting. This paper reviews Underground roof bolting with particular reference to roof bolting and resin capsules. It advocates use of Nano based materials for roof bolts and their grouting which appear to be more advantageous with regard to their high strength and low pollution levels.
\end{abstract}

Keywords—underground roof bolting; safety; resins; styrene, nanotechnology; carbon nanotubes; nano silicates

\section{INTRODUCTION}

Rock re-inforcement in Underground, particularly in Coal mining is now generally practiced by roof bolting. Roof bolt provides support through its ability as a member to enhance the material characteristics of rock strata by increasing the stiffness or the ability of the rock strata to resist movement, when subjected to loading. This necessitates a) roof bolt of superior material property characteristics in terms of strength and stiffness to share the load acting on the rock strata, b)effective bonding between the rock strata and roof bolt to allow load transfer. Factors which influence this bond include the surface properties of the roof bolt (geometry, rib pattern and surface condition), material properties of the grout-cement, resins, silicates etc) and the rock surface characteristics (surface roughness, straightness, voids, etc.). Roof bolting is pre-requisite and an important activity for safety and high percentage of the Coal from Underground Coal mining. Mark [1] enlisted the history of roof bolting in United States where it has become a popular system of support and increased the production and productivity.

Falls of Ground (FOG) occur in spite of intense bolting involving fatalities. Investigations into Falls of Ground (FOG) even after bolting were done by various researchers for formulating and updating the guidelines [2]. Despite all these developments, massive falls are recurring, involving fatalities. In a recent incident, in one of the mines operated by the Singareni Collieries in southern India the fall of intensively bolted roof killed 3 persons and clearing of debris over the bodies in the congested area has taken 3 days (Fig.1, Fig.1a, Fig.1b).

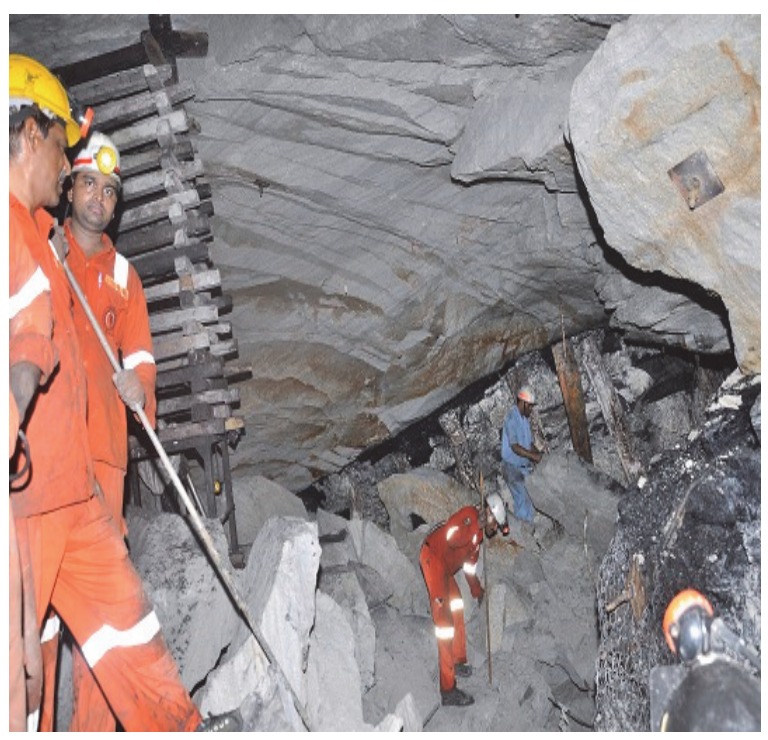

Fig. 1. Congested area after a collapse burying the persons

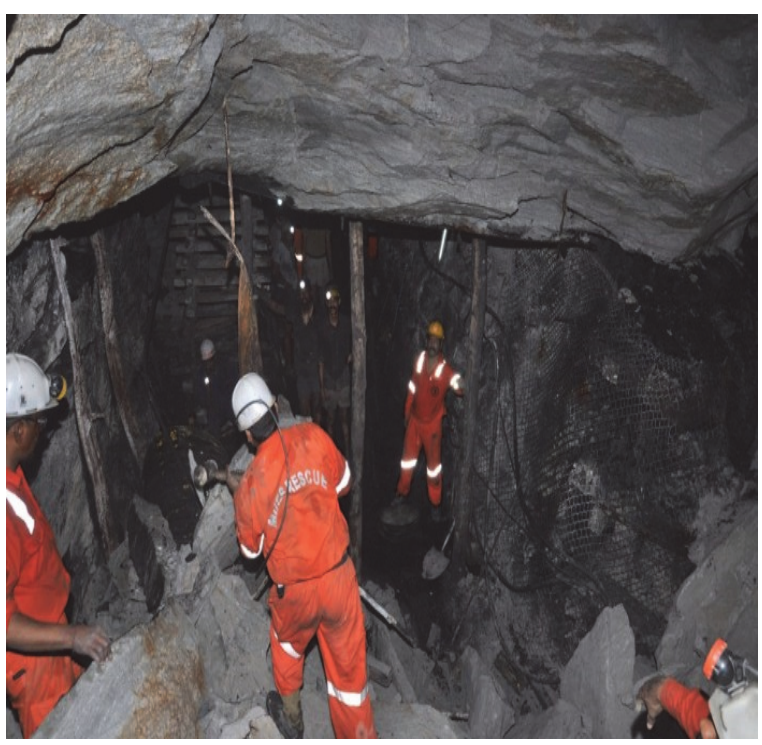

Fig. 1a. Failed bolts at the edge of the fall

Falls of Ground (FOG) still remain a subject for improvement and further research. History of roof support shows that mining industry introduces state of art 
technologies of the corresponding period to improve safety and reduce falls of ground fatalities.

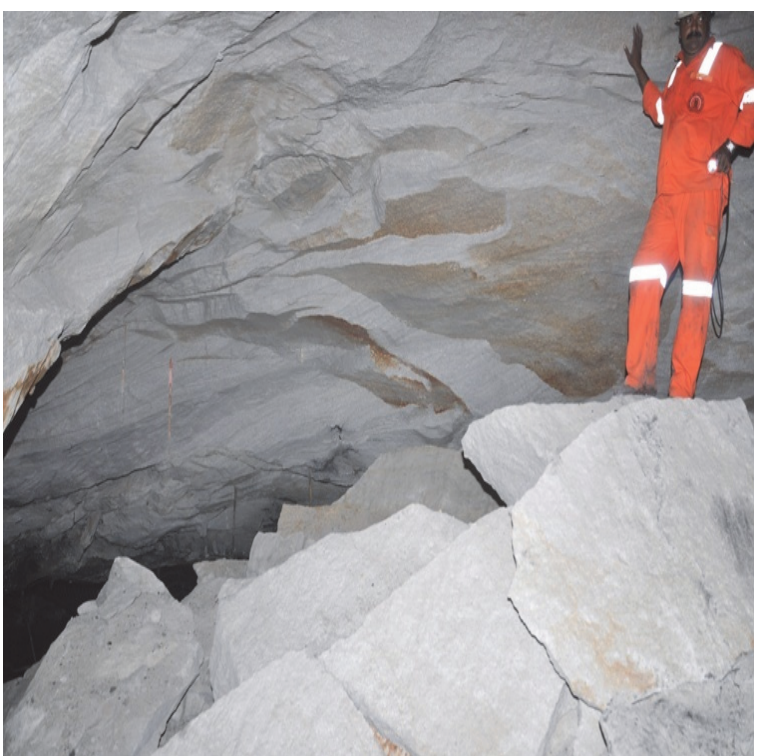

Fig.1b. Height of fall of ground in Underground Mine over a gallery

\section{ANCHOR, MECHANICAL AND FRICTION BOLTS}

Initially roof bolting was developed with the principle of anchoring at the top of the hole and using the friction between the wall of the drill hole and the bolt for load transfer. Types of bolts used were a) split and wedge type, b) expansion shell with screwed plug, c) victor shell type d)expansion shell with screwed plug, e) Bayliss's wedge and sleeve bolt(Fig.2)[3].

Mechanical anchored bolts annual consumption by 1952 was 25 million in 1952[4]. Mechanical bolts don't work in weak strata due to creep of the anchor head making the bolt ineffective. The load transfer is less compared to grouted bolts and these bolts are not suitable for friable strata since they don't bond with rock. This prompted research into embedding the bolt into a material introduced into the holeafter bolt installation to prevent creep of the point anchor

\section{GROUTED BOLTS}

Anchorage with grouting materials are used for effective load transfer. Types of grouts used are a)Quick setting cement capsules, b)Resin capsules, c)silicate capsules.Cement capsules are soaked in water and inserted into the holes. Their initial setting time is $20-30 \mathrm{~min}$. and shelf life is about six months. Due to their slow setting time they are not preferred for green roofs or freshly exposed roofs under which persons cannot be employed immediately after the support.

Due to the slow setting time of cement capsules resin capsules have found application as a grout material. Resin capsules consist of reinforced thyrotrophic polyester resin mastic in one compartment and organic peroxide catalyst separated by a physical barrier in the other compartment. The rotation of rock bolt during installation ruptures the

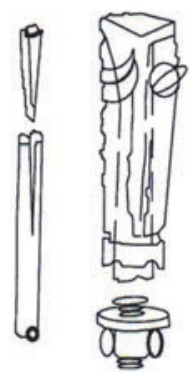

(a) (b)

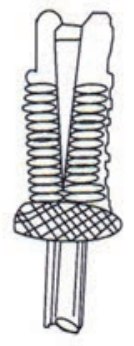

(c)

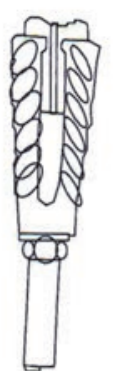

(d)

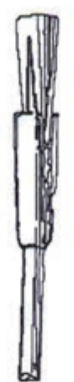

Fig. 2. Anchor type roof bolts

capsule, shreds the skin and mixes the two compartment and the setting time is about $30 \mathrm{sec}$. Their shelf life is six months and storage temperature is $25^{\circ} \mathrm{C}$.

The inside capsule contains the fixing agent. Studies conducted by researchers found that some of the resin is uncured due to which load transfer is considerably reduced. Further, borehole diameter, mastic-catalyst ratio and insertion pressure influence the efficacy of load transfer[4].Presently millions of resin capsules are under use. It is estimated that resin consumed in the US each year can encircle the world at the equator three times if converted to a $22.9 \mathrm{~mm}$ diameter cartridge [5]. However, resins are found to be harmful to men exposed because of generation of styrene from the resins. Styrene is reported to be an health hazard and threshold limits is 50ppm.It affects the body if it is inhaled, is swallowed or comes with eyes or skin[6].Similarly the resin grouting material has got limitations because of the harmful compound which is released as reported by Borat Khassen and polluting the mine ventilation with styrene vapour [7].

A development over the cement capsules and resin capsules using their advantages without their drawbacks is the silicate capsules which are recently becoming popular. Silicate capsules can be further improved with the nanosilicates[8].Addition of sulpho-aluminate cement and nano silica improved and the setting time reduced. with the addition of nano silica. Based on the harmful effects and other disadvantages of resin capsules it is advisable to develop and use silicate based capsules farther for grouting. Further,with combination of nano silica and other nano material, the grouting material can be developed for suiting underground mining conditions with a higher shelf life of three years and above and storage temperatures above $50^{\circ} \mathrm{C}$.

\section{STEEl RoOF Bolts}

Strength of roof bolts, usually ribbed, made of high quality steel range from tensile strength of $0.4-0.8 \mathrm{GPa}$ and Young's module of 150-250GPa with an average density of about 7-8 $\mathrm{g} / \mathrm{cm} 3$. Manufacture of steel bolts from high quality steels and their transport to Underground is being optimized to reduce the bolting cycle and increase productivity. Limitation of steel bolts - due to corrosion is studied by various researchers. 
Li and Lindblad [9] in a study on corrosively classification of the underground environment where rock bolts amount to thousands of tons found that in a humid or water bearing underground environment rock bolts corrode and gradually lose their load bearing capacity.

In a report on Environmental Impact Statement [10]by Green hollow Coal Lease tract by Bureau of Land management, it was observed that during the course of mining operations, many tons of ferrous metals are utilized, particularly the roof bolts, wire mesh and ribbing which cannot be removed as the mine advances or retreats due to safety concerns. These metals would remain in the mine and initiating oxidation time, resulting in some increase in metal concentration in mine water.

Aziz et al [11] in a study on the long term exposure of full size bolts to corrosive mine atmosphere, it was found that failure strength reduction on all the four post corroded bolts was significant, varying between $21 \%$ and $39 \%$. Thus, it is clearly established that corrosion of steel bolts occurs, which affects the strength during use. However, after their use as roof support these bolts are not recovered due to operational, safety and economic issues and these bolts left below ground contaminate mine water, becoming a source for acid mine drainage.

Based on the above studies, it can be clearly concluded that mine water and atmosphere reduces the strength of the bolts by corrosion, thus endangering safety, b) bolts are not recovered due to operational, safety and economic issues, c). roof bolts left in underground pollute the mine water over a period of time increasing metal concentrations. Nano materials which can withstand corrosion and not pollute the mine water can be developed from carbon nanotubes, which otherwise have advantages over steel are discussed with brief introduction of nanotechnology and nanoscience [12].

\section{NANOTECHNOLOGY AND NANOSCIENCE}

Nano, Greek for 'dwarf' means one billionth. Measurement at this level is in nanometers $(\mathrm{nm})$ - billionth of a meter. Fig. 3 shows a typical comparison of nanoscale materials. Different authors have defined Nanotechnology from their field of study. However, as per the definition of the National Nanotechnology Institute [13] which is popularly used Nanotechnology

- Involves research and technology development at the $1 \mathrm{~nm}-100 \mathrm{~nm}$ range.

- Creates and uses structures that have novel properties because of their small size.

- Builds on the ability to control or manipulate at the atomic scale.

Further, nanotechnology deals with creation of materials, structures, devices, systems and architectures of any size by controlling matter at the nanometer length scale and more importantly, by taking advantage of novel properties that arise because of the nanoscale. By Seethamblin and Louis Spirito - The Washington Post Nanotechnology is, at heart, interdisciplinary. It uses chemistry to get the properties of the atoms on the nano level - adding physics and quantum mechanics to the mix

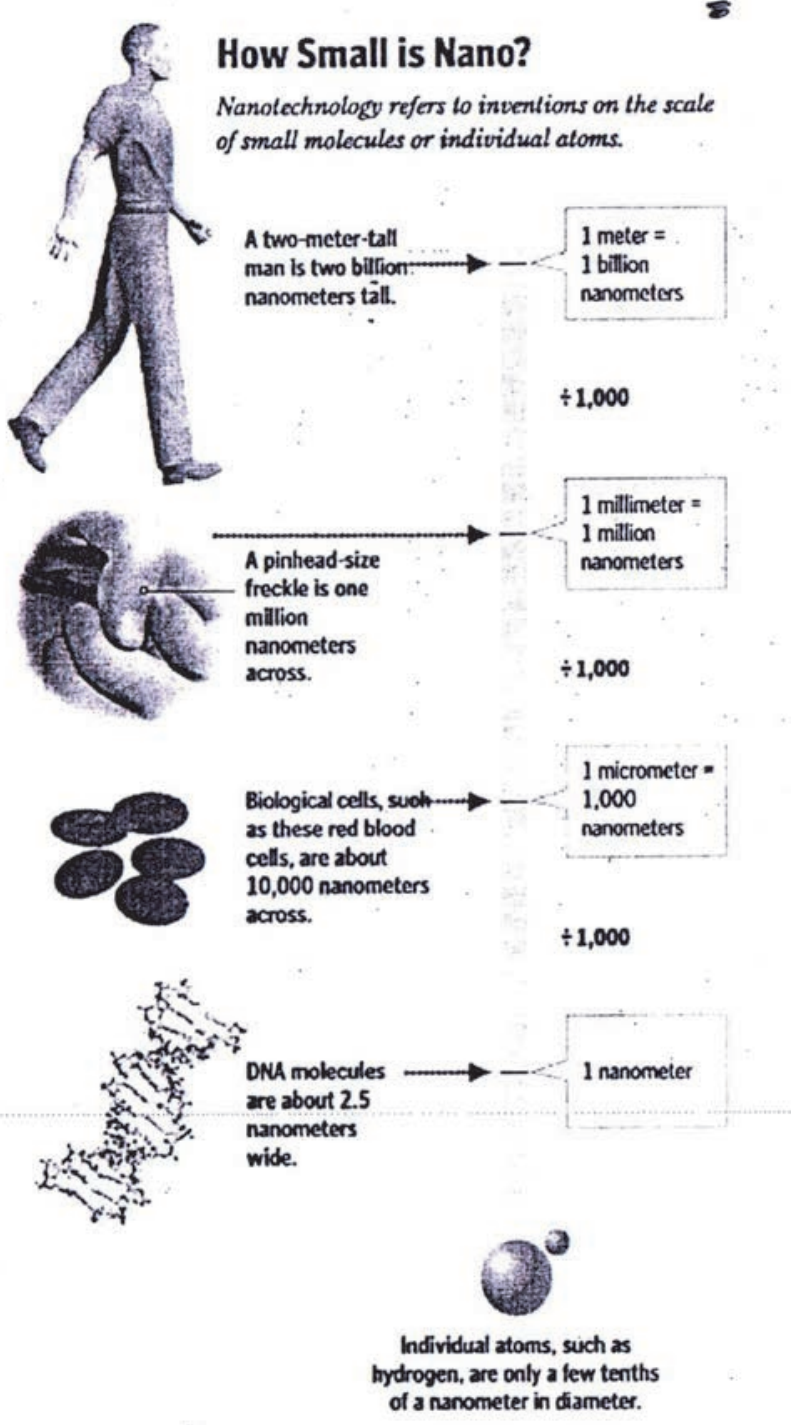

Fig. 3. How Small is Nano (Source: National Science and Technology Ceter)

gives a truer picture of nano materials. Chemists, physicists and medical doctors are working alongside engineers, biologists and computer scientists to determine the applications, direction and development of nanotechnology. In essence nanotechnology in many disciplines is building upon one another.

Drexler [14] in his recent work Radical abundance has explained a revolution in nanotechnology will change civilization. He forecasted that the new technology would be able to produce radically more of people want and at a radically lower cost - in every sense of word - both economical and environmental. According to him - mining, refining and manufacturing will have to be viewed with application of Atomically Precise Manufacturing (APM).

A composite is an engineered material 'composed' of two or more components. There are many types of 
composites, some are made from flakes pressed and glued together (particle board), others are constructed from fiber (fiber glass). Usually, a fiber acts as a backbone for the material and a matrix is chosen for its ability to bond to these fibers. The reason we add the fiber is to enhance the strength of the finished material. Composites are expected to replace bulk material. They are reported to be higher, stronger and cheaper than conventional material [15]. Comparison of Common Material properties is given in Table-1.

TABLE - I COMPARISION OF MATERIAL PROPERTIES COMMONLY USED

\begin{tabular}{|l|c|c|c|}
\hline Material & $\begin{array}{c}\text { Tensile } \\
\text { strength } \\
(\mathbf{G P a})\end{array}$ & $\begin{array}{c}\text { Young's } \\
\text { Modulus } \\
\mathbf{( G P a )}\end{array}$ & $\begin{array}{c}\text { Density } \\
\left(\mathbf{g} / \mathbf{c m}^{\mathbf{3}} \mathbf{)}\right.\end{array}$ \\
\hline Wood & 0.008 & 16 & 0.6 \\
\hline Rubber & 0.025 & 0.05 & 0.9 \\
\hline Steel & 0.4 & 208 & 7.8 \\
\hline Diamond & 1.2 & 1140 & 3.52 \\
\hline Spider Silk & 1.34 & 281 & 1.3 \\
\hline Kevlar & 2.27 & 124 & 1.44 \\
\hline Carbon Fiber & 2.48 & 230 & 2 \\
\hline Glass Fiber & 2.53 & 87 & 2.5 \\
\hline Carbon Nanotube & 200 & 1000 & 2 \\
\hline
\end{tabular}

In view of requirement of rough surface on roof bolts, plain steel bolts were replaced with tar steel bolts for better anchorage in the drilled hole and better anchorage with the grout. To overcome the dis-advantages of steel and resin capsules, it is preferable to use roof bolting manufactured with Nano fibers and Nano silicates, which have the following advantages.

\section{NANO MATERIAl BASEd Roof Bolts - ADVANTAGES}

- Addition of required composites can be used for simulated a rough surface as in the case of ribbed bar steel.

- Material based on carbon nano tubes can avoid pollution due to acid mine drainage occurring in case of steel bolts.

- Better material can be designed for special applications and improving safety in mines.

\section{NANO SilicAtes GROUT MATERIAL}

Nano based silicates can replace resin capsules with the following advantages.

- Shelf life can be increased to 3 years instead of six months in case of resins.

- Storage temperature can be upto $500 \mathrm{o}$ whereas in resins it is to be maintained at $250 \mathrm{C}$ only.

- Setting time can be reduced with addition of nano silica.

- Hazards to miner's due to release of styrene can be avoided.

\section{CONCLUSION AND RECOMMENDATIONS}

Underground roof bolting is a very critical activity. Developments in manufacture of roof bolts and resin capsules have improved safety in underground mines. However, corrosion affects on roof bolts during and after their use and harmful hazards of styrene are the limitations. Nanotechnology which is the latest science for materials and products can be applied for overcoming the above limitations.

Research under $\mathrm{S}$ and $\mathrm{T}$ grant for scientific investigation for development of nano based material for roof bolts and grouting material is required to formulate necessary guidelines for improvement of safety.

\section{ACKNOWLEDGEMENT}

The views expressed in the paper are of the author and not necessarily of the organization he is working. The author expresses thanks to management of SCCL for presentation of this paper.

\section{REFERENCES}

[1] C.Mark, "The introduction of roof bolting to US underground Coal mines",Proc of the 21st International conference on ground control in mining, Morganton, wv,pp. 150-160,2002

[2] IsmetCanbulat, "Evaluation and design of optimum support system in South African Collieries using the probabilistic Design approach"., $\mathrm{Ph} . \mathrm{D}$ Thesis submitted to University of Pretoria, SA.2008.

[3] Notes by Universal Mining School,Cardiff,UK,MK4a on Roof Bolting.

[4] M. Kent, E.David, R.Grey,F.Russell, "The bore hole sleeking test method of resin anchored roof bolt installation". 14th Coal Operators' Conference, University of Wollongong, AIMMM, pp. 118-127,2014.

[5] BolatKhassen"Silicate capsules: a new roof support technology for the Underground mining industry and a comparison with existing roof support technologies."'http://ipkonfiles-wordpress.com,2002

[6] Carl Tom Blevins and Alan A.Campoli, "The origin and history of U.S.Mine Resin",25th International Conference on ground control in mining.,,ISBN 0-939084-56-9,2006.

[7] U.S.Department of Health and Human Services, "Occupational health guideline for styrene", 1978, pp. 1-5.

[8] VenkataRamayya, "Sustainable mining - an application of nanotechnology in roof bolting in coal mines". International Conference on Nanoscience and Technology (ICONSAT 2016), IISER, Pune, p.243, 2016.

[9] C.Li, and Lindblad, "Corrosivity classification of the underground environment" PP69,Rock support and Re-inforcement practice in Mining. 1999 Balkime, Rotterdam ISBN 9058090450, 1999.

[10] Draft Environmental Impact statement on Greens Hollow Coal Lease tract., Bureau of Land Management, Utah, USA, 2009.

[11] Naj Aziz, Peter Craig, Jan Nercik, Faisal I.Hai, "Rock bolt corrosion an experimental study" Coal Operators Conference, University of Wollongong, Australia pp.144-151, 2013.

[12] VenkataRamayya, "Nanotechnology - co and carbon nanotubes" - A proposal for sustainability of Coal under 'Make in India'. Transactions of MGMI (Unpublished), 2016.

[13] The National Nanotechnology Initiative (NNI) - Supplement to the President's 2015 Budget - Committee on Nanoscale Science, Engineering and Technology Committee on Technology, National Science and Technology Council, 2014.

[14] E.Drexler, "Radical Abundance - How a revolution in Nanotechnology will change civilization" Public Affairs, New York, ISBN 978-1-61039-113-9(HC),2013.

[15] Richard Booker, Earl Boysen,"Nanotechnology-The fun and easy way to explore the science of matter's smallest particles"Wiley India Pvt. Ltd,ISBN 978-81-265-0625-5,pp. 96-99, 2010. 